\title{
Uptake of Plasma Fibrinogen into the Alpha Granules of Human Megakaryocytes and Platelets
}

\author{
Paul Harrison," Barry Wilbourn, ${ }^{*}$ Najet Debili, ${ }^{\ddagger}$ William Vainchenker,, Janine Breton-Gorius, ${ }^{\ddagger}$ Andrew S. Lawrie," \\ Jean-Marc Masse, ${ }^{\ddagger}$ Geoffrey F. Savidge, ${ }^{*}$ and Elisabeth M. Cramer \\ *Coagulation Research, The Rayne Institute, St. Thomas’ Hospital, London, United Kingdom; ${ }^{\ddagger}$ Institut Nationale de la Santé et de la \\ Recherche Médicale (INSERM) U 91, Hôpital Henri Mondor, Creteil, France; and ${ }^{\S}$ Département d'Angio-Hématologie \\ and INSERM U 150, Hopital Lariboisière, 75010, Paris, France
}

\begin{abstract}
The origin of platelet $\alpha$-granule fibrinogen (Fg), whether from endogeneous synthesis or exogeneous derivation, remains unknown. Although Fg biosynthesis by megakaryocytes (MK) has been suggested, recent studies have demonstrated that certain $\alpha$-granular proteins originate primarily from plasma. To study the origin of $\alpha$-granule Fg, platelet-associated Fg was measured by ELISA and Western blotting, and localized by immunofluorescence and immunoelectron microscopy in a patient with symptomatic congenital afibrinogenemia before and after replacement therapy with cryoprecipitate. $\alpha$-Granule $\mathbf{F g}$ was detected in the majority of platelets as early as $24 \mathrm{~h}$ postinfusion, suggesting that direct platelet uptake was occurring. Platelet $\mathrm{Fg}$ reached a maximum value of $42.5 \%$ of normal values at $3 \mathrm{~d}$ postinfusion and was localized in the $\alpha$-granules, while plasma levels followed a typical half-life profile. Significant $\alpha$-granule $\mathrm{Fg}$ was still detectable at $13 \mathrm{~d}$ postinfusion, with plasma Fg virtually absent. Studies on cultured CFU-MKs from the patient also confirmed that MKs can incorporate exogeneous Fg into $\alpha$-granules. These results indicate that platelet $\alpha$-granule $\mathrm{Fg}$ can be derived from the circulating plasma pool and that Fg uptake can occur in both platelets and MKs.
\end{abstract}

\section{Introduction}

Platelet $\alpha$-granules are known to contain a diversity of proteins including coagulation factors, which are of fundamental importance in hemostasis (1). Initially these proteins were assumed to originate from endogeneous synthesis during megakaryocyte (MK) ${ }^{1}$ development (2). Recent evidence, however, has demonstrated that certain plasma proteins such as albumin, Ig, and the tracer protein horseradish peroxidase (HRP) can be incorporated into $\alpha$-granules (3-5). Although fibrinogen $(\mathrm{Fg})$ synthesis by MKs has been suggested (6-8), recent in vitro studies have demonstrated that $\mathrm{Fg}$ is packaged in the $\alpha$-granules of cultured MK at a later stage than other synthe-

Address correspondence and reprint requests to Dr. Elisabeth Cramer, Département d'Angio-Hématologie, Hôpital Lariboisière, 75010, Paris, France.

Received for publication 24 April 1989 and in revised form 23 June 1989

1. Abbreviations used in this paper: $\mathrm{Fg}$, fibrinogen; HRP, horseradish peroxidase; IEM, immunoelectron microscopy; MK, megakaryocyte.

J. Clin. Invest.

(C) The American Society for Clinical Investigation, Inc.

$0021-9738 / 89 / 10 / 1320 / 05 \$ 2.00$

Volume 84, October 1989, 1320-1324 sized proteins and only occurs when an exogenous source of the protein is present (9). Despite earlier in vivo and in vitro studies that failed to demonstrate $\mathrm{Fg}$ exchange between $\alpha$ granules and plasma $(10,11)$, recent data involving in vivo defibrination of rats and the infusion of human $\mathrm{Fg}$ into guinea pigs suggest that endocytosis of plasma $\mathrm{Fg}$ occurs in the MK with subsequent expression of the protein in circulating platelets $(12,13)$.

To elucidate more conclusively the origin of platelet $\mathrm{Fg}$, quantitative and qualitative measurements of platelet and plasma $\mathrm{Fg}$ were performed for up to $24 \mathrm{~d}$ in a symptomatic patient with congenital afibrinogenemia after replacement therapy with cryoprecipitate. In this manner, the kinetics of a putative $\mathrm{Fg}$ uptake mechanism into the MKs and platelets could be studied. In vitro experiments were also performed on cultured MKs from the same patient before therapy. The experimental data provide the first clear in vivo evidence for the endocytic uptake of plasma Fg into human platelet $\alpha$-granules.

\section{Methods}

Patient. A 27-yr-old woman with a known family history of autosomal recessive afibrinogenemia and a life-long history of bleeding symptoms was admitted with menorrhagia. Representative basal plasma Fg levels were $1.8 \mu \mathrm{g} / \mathrm{ml} \mathrm{Fg}$ (antigen by ELISA), $<9 \mathrm{mg} / \mathrm{dl}$ clottable $\mathrm{Fg}$ (Clauss technique) with a prolonged thrombin time ratio $>10.0$, international normalized ratio $>11.0$, and a bleeding time $>30 \mathrm{~min}$ (Ivy method). The patient was not receiving oral contraceptives or any other prescribed medication.

Infusion studies. We studied this patient on four separate occasions when she required treatment for severe menorrhagia. Platelet $\mathrm{Fg}$ was assessed qualitatively by immunoelectron microscopy (IEM) and quantitatively by ELISA and Western blotting of platelet lysates. In these studies regular samples were taken up to $24 \mathrm{~d}$ postinfusion of cryoprecipitate (3.4-5.3 g Fg).

Platelet preparation procedures. Venous blood was obtained by clean venipuncture using the two-syringe technique, and anticoagulated in $1: 10 \mathrm{vol}$ of $3.2 \%$ trisodium citrate and EDTA $(10 \mathrm{mM})$. Platelet-rich plasma was prepared by centrifugation at $250 \mathrm{~g}$ for $20 \mathrm{~min}$. Platelets and washed buffy coats were applied to a discontinuous arabinogalactan gradient using a modification of the method of Gralnick et al. (14). The differentiation of platelet membrane associated from internalized $\mathrm{Fg}$ was ensured by enzymatic digestion of surface $\mathrm{Fg}$ on intact platelets with $1 \mathrm{mg} / \mathrm{ml}$ pronase $(4 \mathrm{U} / \mathrm{mg}$; Sigma Chemical Co., St. Louis, MO) using a BSA control sample for $4 \mathrm{~h}$ at $4^{\circ} \mathrm{C}$ before washing and lysis. After adjustment of the platelet count to $10^{6} / \mu \mathrm{l}$, the cells were lysed with $1: 40$ vol of $20 \%$ Triton at $37^{\circ} \mathrm{C}$ for $1 \mathrm{~h}$ and subsequently stored at $-70^{\circ} \mathrm{C}$. Centrifugation at $10,000 \mathrm{~g}$ was necessary to remove platelet membranes before analysis. The efficiency of removal of plasma proteins was assessed in control samples by the addition of ${ }^{125} \mathrm{I}-\mathrm{Fg}$ (Amersham Corp., Arlington Heights, IL) to whole blood before platelet lysis. Quantitation of Fg in normal platelet lysates from 20 healthy donors was performed to establish a reference range.

IEM. 1 vol blood was taken into tubes containing $9 \mathrm{vol}$ of fixative (3\% glutaraldehyde in $0.1 \mathrm{M}$ phosphate buffer, $\mathrm{pH} 7.2$ ) according to 
Stenberg et al. (15). Cells were fixed for $40 \mathrm{~min}$ at $20^{\circ} \mathrm{C}$, washed three times in phosphate buffer $(0.1 \mathrm{M}, \mathrm{pH} 7.4)$, and embedded in glycolmethacrylate $(16,17)$. Cultured MKs were fixed and treated the same way. Immunocytochemistry was performed on thin sections according to the method of De Mey (18). Sections were incubated for $2 \mathrm{~h}$ in the presence of rabbit anti-human vWf (DAKOPATTS, Copenhagen, Denmark) or Fg (Cappel laboratories, Cochranville, PA). Goat antirabbit IgG coupled to 5-nm gold particles (GARG5; Janssen Pharmaceutica, Beerse, Belgium) was used as the second antibody. Samples were assessed without knowledge of their time of collection. 50 platelet sections were observed in each sample. Platelets were considered positive for Fg when at least two of five or more $\alpha$-granules in platelets were labeled.

Culture and immunofluorescence procedures. PBMC from the patient (preinfusion) were separated by Ficoll-Hypaque centrifugation and cultured in Iscove's medium, 1\% BSA, 5\% PHA-lymphocyte-conditioned medium, and either $10 \%$ aplastic plasma or $10 \%$ aplastic serum. After $13 \mathrm{~d}$ culture cells were recovered, cytocentrifuged, and fixed for $1 \mathrm{~min}$ with methanol. Platelet samples were assessed in the same manner. They were subsequently double-labeled using rabbit anti-human $\mathrm{Fg}$ (Cappel Laboratories) and a pool of anti-vWf MAbs (a generous gift of Dr. D. Meyer, INSERM U 143, Hôpital de Bicetre, Paris, France). Goat anti-rabbit IgG (rhodamine conjugated; Nordic Immunology, Tillbury, The Netherlands) and sheep anti-mouse $F\left(a^{\prime}\right)_{2}$ fragments (fluorescein conjugated; Selenius, Hawthorn, Australia) were used as the secondary antibodies.

Immunological methods. Plasma and platelet $\mathrm{vWf}$ and $\mathrm{Fg}$ were assayed by standard ELISA techniques using polyclonal monospecific antibodies (Dako, High Wycombe, UK). Discontinuous electrophoresis in $2 \%$ agarose gels was performed on plasma and platelet lysates by a modification of the method of Ruggeri and Zimmerman (19). After electrophoresis the proteins were rapidly transferred to nitrocellulose by electroblotting (20). Fg and vWf-Ag were visualized using rabbit anti-human $\mathrm{Fg}$ or vWf-Ag as first antibody (Dako) and HRP-conjugated swine anti-rabbit IgG (Dako) as the second antibody, and developed with 4-chloro-naphthol and $\mathrm{H}_{2} \mathrm{O}_{2}$.

\section{Results}

To study the time course of the appearance of intracellular $\mathrm{Fg}$, a combination of immunocytochemical techniques and biochemical studies of washed platelets, platelet lysates, and plasma were performed at various time intervals up to $24 \mathrm{~d}$ postinfusion on four separate occasions.

Biochemical measurements. ELISA measurements and Western blotting demonstrated the absence of $\mathrm{Fg}$ in the patient's platelets before therapy, with trace concentrations of $\mathrm{Fg}$ in the plasma ( $0.08 \%$ normal). Plasma $\mathrm{Fg}$ reached almost $50 \%$ of normal levels immediately after infusion and followed a typical half-life decay. In contrast, platelet $\mathrm{Fg}$ levels remained low immediately after infusion and slowly increased, reaching a maximum of $\sim 40 \%$ normal between 2 and $4 \mathrm{~d}$ postinfusion while plasma levels were falling. After $5 \mathrm{~d}$ the platelet $\mathrm{Fg}$ level began to decrease, reaching $18.7 \%$ of normal levels at $7 \mathrm{~d}$ postinfusion. Fig. 1 shows a representative profile of plasma and platelet $\mathrm{Fg}$ after infusion of $\sim 5.2 \mathrm{~g}$ of $\mathrm{Fg}$ in cryoprecipitate. At $13 \mathrm{~d}$ postinfusion the platelets were still found to contain significant intracellular $\mathrm{Fg}$ as assessed by ELISA $(11.8 \%$ normal), whereas plasma $\mathrm{Fg}$ returned to near basal levels $(1.25 \%)$. Even at $24 \mathrm{~d}$ postinfusion trace amounts of platelet $\mathrm{Fg}$ were still detectable (2.0\%). The degree of Fg staining by Western blotting mirrored the antigen levels (results not shown). Comparison of platelet vWf-Ag levels by ELISA and Western blotting revealed that there were no significant differences in lysate samples, and platelet counts remained constant throughout the study (293-302 $\times 10^{9} /$ liter $)$.

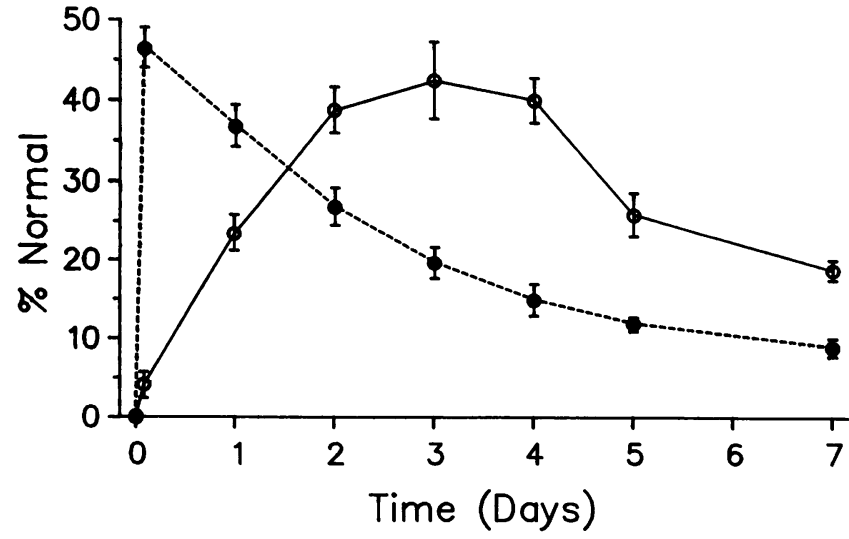

Figure 1. Time course of plasma and platelet lysate Fg levels (mean $\pm \mathrm{SD}$ ) following infusion of cryoprecipitate $(5.2 \mathrm{~g} \mathrm{of} \mathrm{Fg}$ ) into a patient with symptomatic congenital afibrinogenemia. Plasma $\mathrm{Fg}(\bullet)$ was expressed as a percentage of normal pooled plasma $(2.1 \mathrm{mg} / \mathrm{ml}$ $\mathrm{Fg}$ ). Platelet $\mathrm{Fg}$ ( $\mathrm{O}$ was expressed as a percentage of an established normal range from 20 healthy donors $\left(74.55 \pm 20.7 \mu \mathrm{g} / 10^{9}\right.$ platelets).

Immunocytochemistry. Before treatment the patient's platelets demonstrated no detectable $\mathrm{Fg}$ by immunofluorescence (results not shown) and IEM (Fig. $2 a$ ). However, in the same sample vWf-Ag was detectable in the platelet $\alpha$-granules according to its characteristic eccentric localization (Fig. $2 a$, inset). At $2 \mathrm{~h}$ postinfusion $\mathrm{Fg}$ labeling was still negative in the $\alpha$-granules by IEM. Immunofluorescence staining could detect a typical granular pattern of $\mathrm{Fg}$ labeling in the platelets at $24 \mathrm{~h}$ postinfusion, with $80 \%$ of platelet sections positive for $\mathrm{Fg}$ by IEM. After $48 \mathrm{~h}$ positively labeled $\alpha$-granules were found in $92 \%$ of platelets by IEM (Fig. $2 b$ ). At 3 and 4 d postinfusion $100 \%$ of platelets were positive with the number of gold particles per platelet greater than in earlier samples. The percentage of labeled platelets started to decrease after $5 \mathrm{~d}$. At $13 \mathrm{~d}$ postinfusion $12 \%$ of platelet sections were still positive for $\mathrm{Fg}$ in the $\alpha$-granules by IEM, whereas at $24 \mathrm{~d}$ postinfusion all platelets were negative for $\mathrm{Fg}$.

Megakaryocyte culture studies. CFU-MKs from the patient were grown in liquid culture. MKs identified by their positive immunostaining for vWf (Fig. $3 a$ ) represented $\sim 2 \%$ of the total cell population. Cells grown in the presence of plasma were able to express $\mathrm{Fg}$ as shown by immunofluorescence (Fig. $3 b$ ) or IEM (Fig. 4). In contrast, MKs grown in the presence of serum remained negative for $\mathrm{Fg}$ but with normal labeling for vWf-Ag.

Mathematical modeling. A simplistic model of the MK/ platelet incorporation of $\mathrm{Fg}$ was calculated from the data in Fig. 1 to estimate the relative importance of MK versus platelet uptake (Fig. 5). The percentage of Fg-positive platelets derived from MK uptake was estimated by assuming that $10 \%$ of circulating platelets were replaced with new platelets every 24 $h$. This model assumed that there was no significant time delay between $\mathrm{MK} \mathrm{Fg}$ uptake and thrombopoiesis, that the positive platelets were saturated with $\mathrm{Fg}$ (i.e., $74.55 \mu \mathrm{g} / 10^{9}$ platelets), and that $\mathrm{Fg}$ uptake only occurred for the first $4 \mathrm{~d}$ after therapy while plasma Fg levels were high. The platelet uptake curve was calculated by subtracting the MK curve from the observed platelet Fg levels. The resulting curves (Fig. 5) clearly demonstrate that both MK and platelet uptake were occurring during the first $4 \mathrm{~d}$ after therapy. Exclusive MK uptake appeared to be operative after $4 \mathrm{~d}$ postinfusion. 

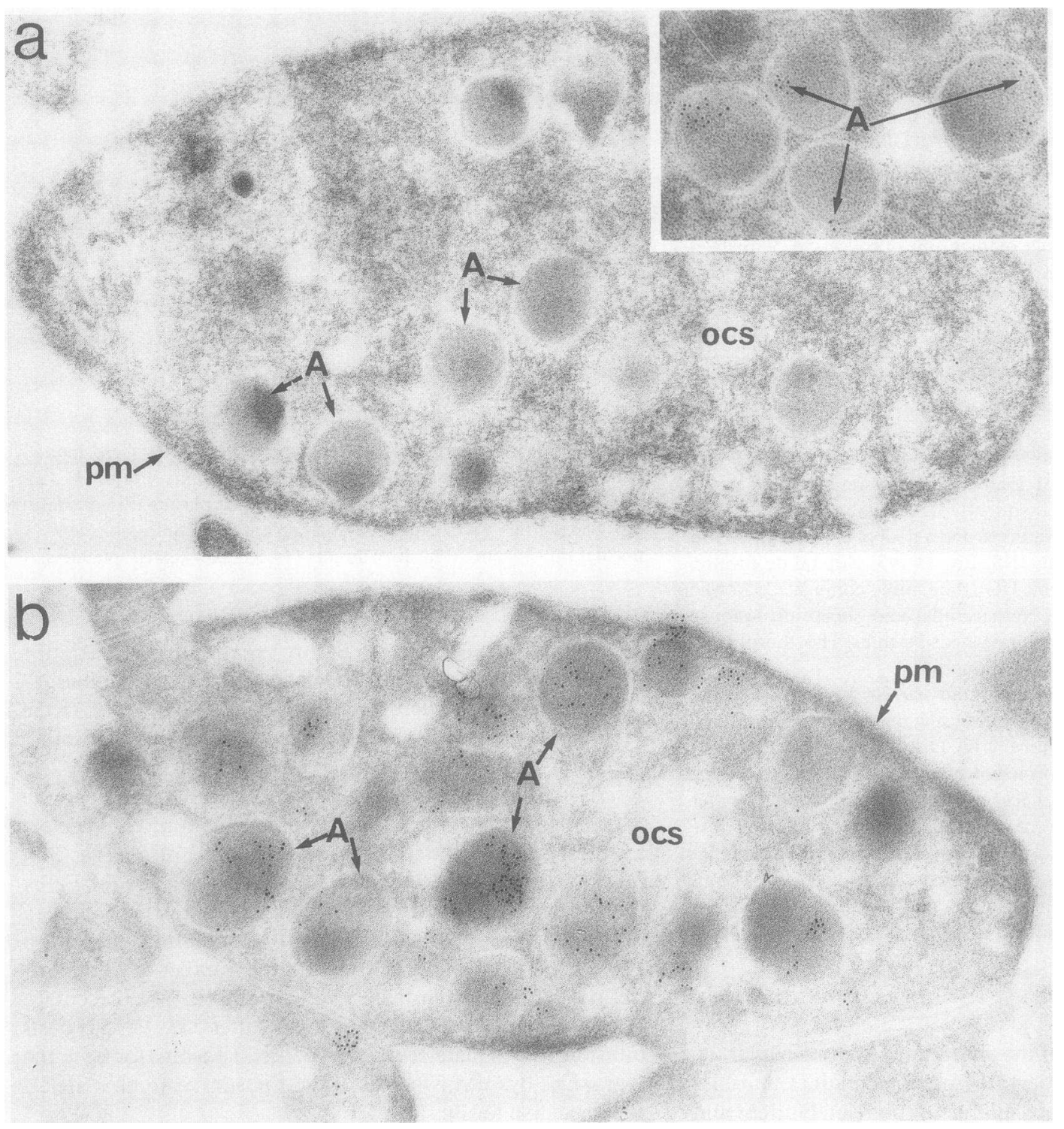

Figure 2. Immunogold labeling for $\mathrm{Fg}$ in platelets from an afibrinogenemic patient. (a) No $\mathrm{Fg}$ was seen in the $\alpha$ granules $(A)$ before treatment, whereas vWf was detected according to its specific eccentric localization. (b) $48 \mathrm{~h}$ after infusion of cryoprecipitate $\mathrm{Fg}$ was present within the $\alpha$-granules $(A)$. The plasma membrane $(\mathrm{pm})$ and open canulicular system (ocs) were not labeled. $\times 48,000$.

\section{Discussion}

In this study we combined biochemical and immunocytochemical techniques to study whether plasma Fg could be incorporated within platelet and MK $\alpha$-granules. The experimental data derived from the study of platelets from a patient with congenital afibrinogenemia demonstrate that the incorporation of plasma Fg into $\alpha$-granules occurs as early as $24 \mathrm{~h}$ postinfusion of cryoprecipitate. Platelet levels continued to rise and reached a plateau of $\sim 40 \%$ normal with $100 \%$ of positive platelets after 3-4 $\mathrm{d}$. The early high proportion $(80 \%)$ of positive platelets at $24 \mathrm{~h}$ is much greater than would be expected if Fg uptake were occurring exclusively in the MK, as only a maximum of $10-14 \%$ of circulating platelets would be positive. However, the persistence of detectable $\mathrm{Fg}$ within the platelets and the return of plasma levels to basal levels at $13 \mathrm{~d}$ posttreatment also support the possibility of $\mathrm{Fg}$ uptake occurring in the MKs. Perhaps both mechanisms are occurring in vivo since mature $\alpha$-granules of normal bone marrow MKs were shown to contain less stainable Fg by IEM than in circulating platelets (9). The relative importance of MK versus platelet uptake was estimated by the application of a simple mathematical model based on normal platelet kinetics (Fig. 5).
The resulting curves suggested that a combination of both MK and platelet uptake of $\mathrm{Fg}$ was operative until $4 \mathrm{~d}$ postinfusion, after which only exclusive MK uptake of Fg occurred. However, the model is only an approximate estimate of MK/platelet uptake, particularly as the platelet kinetics were likely to be abnormal in the patient studied because of the severe menorrhagia before therapy. Previous studies may have failed to
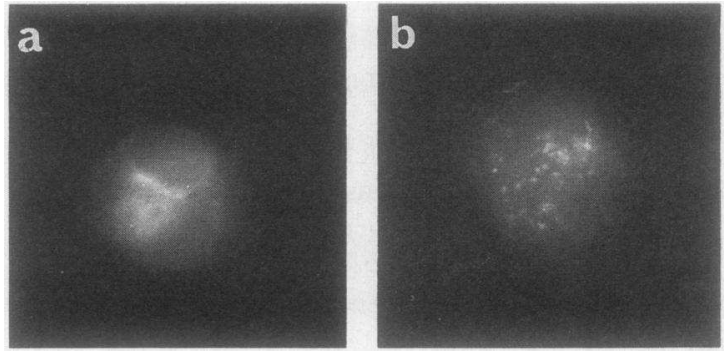

Figure 3. Double immunofluorescent labeling for $\mathrm{vWf}$ and $\mathrm{Fg}$ in 13-d cultured afibrinogenemic MKs. In the presence of plasma, cells identified as MKs by their $\mathrm{vWf}$ content $(a)$ were strongly positive for $\mathrm{Fg}(b)$. 


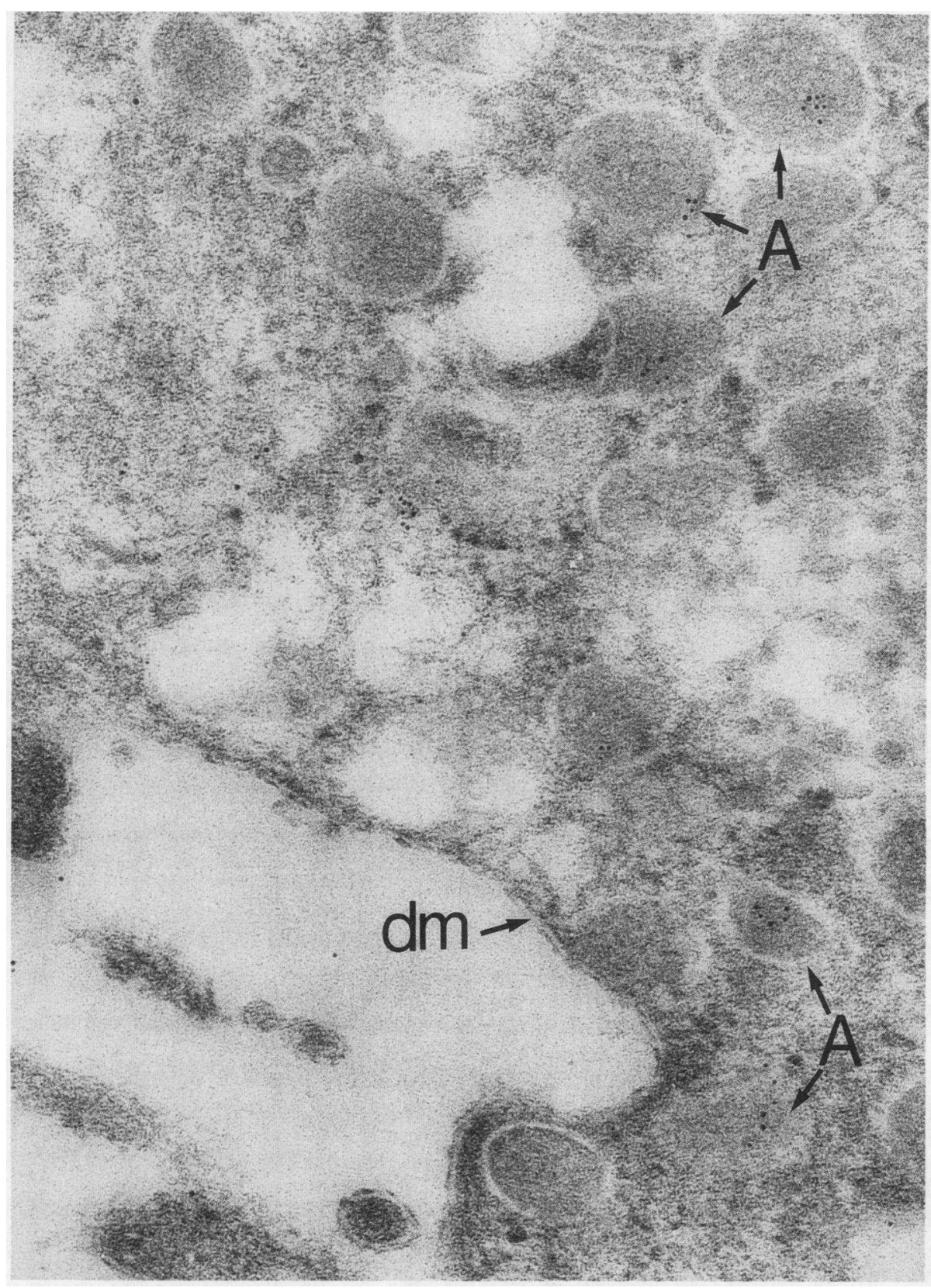

Figure 4. Part of a 12-d cultured MK from the afibrinogenemic patient grown in the presence of normal plasma and immunolabeled for $\mathrm{Fg}$. Labeling is present in some of the $\alpha$-granules $(A)$ of this large MK containing a prominent demarcation membrane system $(d m) . \times 48,000$. demonstrate transfer of $\mathrm{Fg}$ from plasma to platelets due to insufficient consideration for time-dependent platelet uptake $(10,11)$. The ability of MKs to incorporate other platelet $\alpha$ granule proteins such as $\mathrm{Ig}$, albumin $(3,5,13)$, and an exogenous tracer protein, HRP, (4) has already been established. Studies performed on animal models also suggested that $\mathrm{Fg}$ uptake occurs in the MK $(12,13)$. Recent in vitro studies with cultured MKs have demonstrated that the appearance of $\mathrm{Fg}$ in the $\alpha$-granules, subsequent to the synthesized proteins thrombospondin and vWf, is dependent on an exogenous source of $\mathrm{Fg}$ (9). The in vitro results obtained with the afibrinogenemic MKs that are unable to synthesize Fg confirmed these observations and thus discounted the possibility of upregulation of Fg expression.

It is intriguing to speculate on the mechanisms of MK and platelet endocytosis of $\mathrm{Fg}$, particularly as platelets congenitally deficient in the Fg receptor Gp IIb/IIIa, as in Glanzmann's thrombasthenia, do not contain platelet $\alpha$-granule $F g(21)$.
Although platelet activation is a prerequisite site for $\mathrm{Fg}$ binding to exposed GpIIb/IIIa (22), perhaps Fg can still interact with partially exposed GpIIb/IIIa on resting circulating platelets in a time-dependent manner (23). Recent evidence demonstrates that resting platelets also contain a dynamic cycling pool of GpIIb/IIIa (24), which could transport plasma Fg into the $\alpha$-granules. Fg possesses six potential GpIIb/IIIa binding domains, one per $\gamma$-chain and two per $\alpha$-chain (25), of which four probably mediate multivalent attachment to the platelets (26), a possible prerequisite for endocytosis. Normal $\gamma$-chains are necessary to support normal ADP-induced platelet aggregation (27), but may also be critical for internalization of $\mathrm{Fg}$, as both normal platelets and those from patients with certain forms of dysfibrinogenemia (such as fibrinogen Paris I) do not express any of the circulating variant $\gamma$-chains of $\mathrm{Fg}(28,29)$. However, it is also conceivable that the uptake of $\mathrm{Fg}$ is via a non-Gp IIb/IIIa-like receptor, which could also mediate the uptake of albumin, Ig, and HRP, its concentration and reten- 


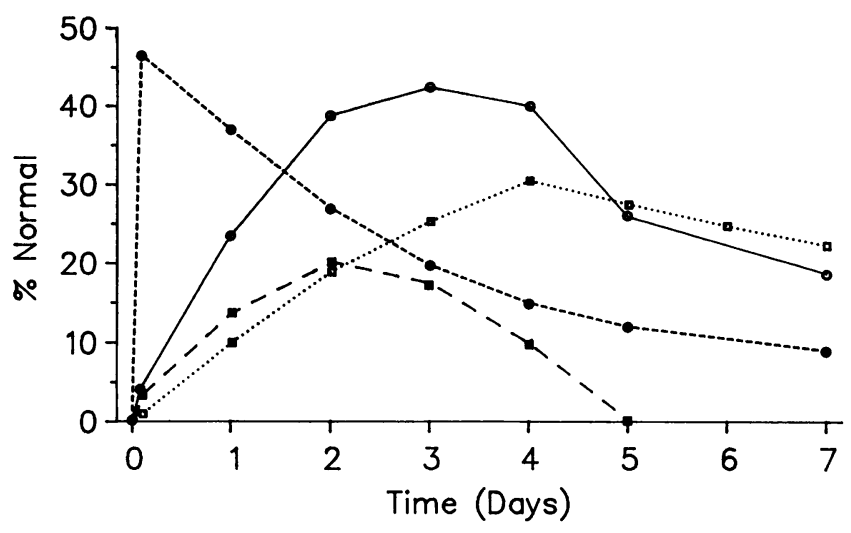

Figure 5. Mathematical model estimating the time course of the relative incorporation of $\mathrm{Fg}$ into $\mathrm{MKs}$ and circulating platelets after infusion of cryoprecipitate into a patient with congenital afibrinogenemia (derived from data of Fig. 1). The percent of MK-derived platelets was derived by assuming that $10 \%$ of circulating platelets were replaced from the bone marrow every $24 \mathrm{~h}$. The percent of $\mathrm{Fg}$ uptake into circulating platelets was calculated by substracting the MK-derived curve from the observed platelet $\mathrm{Fg}$ levels. ๑, plasma $\mathrm{Fg}$; $\mathrm{O}$, platelet $\mathrm{Fg} ; \square$, MK model; $a$, platelet model.

tion within the $\alpha$-granule being under the specific control of GpIIb/IIIa. Finally, although we have demonstrated that platelets and MKs can incorporate exogenous $\mathrm{Fg}$, the study was performed in a symptomatic patient with congenital afibrinogenemia and its relevance to normal physiology remains to be elucidated.

\section{Acknowledgments}

We are grateful to Prof. James N. George for his expert advice in the preparation of this manuscript.

This work was supported by grants from the Wellcome Trust $(17208 / 15)$ and La Fondation de France.

\section{References}

1. Kaplan, K. L., M. J. Broekman, A. Chernoff, G. R. Lesnik, and M. Drillings. 1979. Platelet $\alpha$-granule proteins: studies on release and subcellular localization. Blood. 53:604-618.

2. Kieffer, N., J. Guichard, J. P. Farcet, W. Vainchenker, and J. Breton-Gorius. 1987. Biosynthesis of major platelet proteins in human blood platelets. Eur. J. Biochem. 164:189-195.

3. George, J. N., S. Saucerman, S. P. Levine, and L. K. Knieriem. 1985. Immunoglobulin $G$ is a platelet $\alpha$-granule secreted protein. $J$. Clin. Invest. 76:2020-2025.

4. Handagama, P. J., J. N. George, M. A. Shuman, R. P. McEver, and D. F. Bainton. 1987. Incorporation of a circulating protein into megakaryocyte and platelet granules. Proc. Natl. Acad. Sci. USA. 84:861-865.

5. George, J. N., and S. Saucerman. 1988. Platelet IgG, IgA, IgM, and albumin. Correlation of platelet and plasma concentrations in normal subjects and in patients with ITP or dysproteinemia. Blood. 72:362-365.

6. Leven, R. M., P. K. Schick, and A. M. Budzinkski. 1985. Fibrinogen biosynthesis in isolated guinea pig megakaryocytes. Blood. 65:501-504.

7. Belloc, F., P. Hourdille, P. Fialon, M. R. Boisseau, and J. Soria. 1985. Fibrinogen synthesis by megakaryocyte rich human marrow cell concentrates. Thromb. Res. 38:341-351.

8. Uzan, G., G. Courtois, Z. Stanckovic, G. R. Crabtree, and G. Marguerie. 1986. Expression of the fibrinogen genes in rat megakaryocytes. Biochem. Biophys. Res. Commun. 140:543-549.

9. Cramer, E. M., N. Debili, J. F. Martin, A. M. Gladwin, J. Breton-Gorius, P. Harrison, G. F. Savidge, and W. Vainchecker. 1989. Uncoordinated expression of fibrinogen compared with thrombo- spondin and von Willebrand factor in maturing human megakaryocytes. Blood. 73:1123-1129.

10. Karpatkin, M., L. Howard, and S. Karpatkin. 1984. Studies on the origin of platelet associated fibrinogen. J. Lab. Clin. Med. 104:223-237.

11. James, H. L., P. Ganguly, and C. W. Jackson. 1977. Characterization and origin of fibrinogen in blood platelets: a review with recent data. Thromb. Haemostasis. 38:939-953.

12. Handagama, P., R. Shuman, M. A. Shuman, and D. F. Bainton. 1988. In vivo defibrination results in markedly decreased levels of fibrinogen in megakaryocytes and platelets in rats. Blood. 72:323a. (Abstr.)

13. Handagama, P., M. A. Shuman, and D. F. Bainton. 1987. Uptake of circulating albumin, IgG and fibrinogen by guinea pig megakaryocytes in vivo. Blood. 70:154a. (Abstr.)

14. Gralnick, H. R., S. Y. Williams, L. P. Mckeown, P. Maisoneuve, C. Jeanneau, Y. Sultan, and M. E. Rick. 1985. In vitro correction of the abnormal multimeric structure of von Willebrand factor in Type IIA von Willebrand's disease. Proc. Natl. Acad. Sci. USA. 82:5968-5972.

15. Stenberg, P. E., M. A. Shuman, S. P. Levine, and D. F. Bainton. 1984. Redistribution of $\alpha$-granules and their contents in thrombinstimulated platelets. J. Cell Biol. 98:748-760.

16. Cramer, E. M., D. Meyer, R. Le Menn, and J. Breton-Gorius. 1985. Eccentric localization of von Willebrand factor with a tubular structure of platelet $\alpha$-granule resembling that of Weibel-Palade bodies. Blood. 66:710-713.

17. Leduc, E. H., and W. Bernhard. 1967. Recent modification of the glycol-methacrylate embedding procedure. J. Ultrastruct. Res. 19:196-199.

18. De Mey, J. 1983. A critical review of light and electron microscopy immunocytochemical techniques used in neurobiology. J. Neurosci. Methods. 7:1-18.

19. Ruggeri, Z. M., and T. S. Zimmerman. 1981. The complex multimeric composition of Factor VIII/von Willebrand factor. Blood. 57:1140-1143.

20. Dalton, R. G., A. Lasham, and G. F. Savidge. 1988. A new rapid semi-dry blotting technique for multimeric sizing of von Willebrand factor. Thromb. Res. 50:345-349.

21. Belloc, F., E. Heilman, R. Combrie, M. R. Boisseau, and A. T. Nurden. 1987. Protein synthesis and storage in human platelets: a defective storage of fibrinogen in platelets with Glanzmann's thrombasthenia. Biochim. Biophys. Acta. 925:218-225.

22. Marguerie, G. A., E. F. Plow, and T. S. Edgington. 1979. Human platelets possess an inducible and saturable receptor for fibrinogen. J. Biol. Chem. 254:5357-5363.

23. Coller, B. S. 1986. Activation affects access to the platelet receptor for adhesive glycoproteins. J. Cell Biol. 103:451-456.

24. Wencel-Drake, J. D. 1988. Plasma membrane GPIIb/IIIa. Evidence for a cycling receptor pool. Blood. 72:344a. (Abstr.)

25. Hawinger, J., S. Timmons, M. Kloczewiak, D. D. Strong, and R. F. Doolittle. 1982. Gamma and alpha chains of human fibrinogen possess sites reactive with human platelet receptors. Proc. Natl. Acad. Sci. USA. 79:2068-2071.

26. Furlan, M. 1988. Structure of fibrinogen and fibrin. In Fibrinogen, Fibrin Stabilisation and Fibrinolysis. J. L. Francis, editor. Ellis Horwood Ltd., Chichester, England. 17-64.

27. Denninger, M. H., M. Jandrot-Perrus, J. Elion, O. Bertrand, G. A. Homandberg, M. W. Mosesson, and M. C. Guillin. 1987. ADPinduced platelet aggregation depends on the conformation or availability of the terminal gamma chain sequence of fibrinogen. Study of the reactivity of fibrinogen Paris 1. Blood. 70:558-563.

28. Kunicki, T. J., P. J. Newman, D. L. Amrani, and M. W. Mosesson. 1985. Human platelet fibrinogen. Purification and hemostatic properties. Blood. 66:808-815.

29. Jandrot-Perrus, M., M. W. Mosesson, M. H. Denninger, and D. Menache. 1979. Studies of platelet fibrinogen from a subject with a congenital fibrinogen abnormality (fibrinogen Paris I). Blood. 54:1109-1116. 